\title{
Colégio Luso-Francês, Porto
}

\author{
E N T R E I S TA C O N U Z I A POR CARLOS FOLHADELA S I M Õ E
}

Desde o átrio de entrada que se respira uma atmosfera de muita tranquilidade, calma e organização. Estamos no Colégio Luso-Francês, localizado na cidade Invicta. Fomos gentilmente recebidos pela Madre Superiora que desempenha ainda as funções de Directora Peda- gógica, Irmã Helena Moreira. Acompanharam-nos na entrevista a Dr. ${ }^{a}$ Noémia Almeida, professora do $12 .^{\circ}$ ano e o Dr. Carlos Azevedo, Coordenador do Departamento de Ciências Exactas, da Natureza e Tecnológicas.
Irmã Helena Moreira, agradecia que nos apresentasse o Colégio Luso-Francês que superiormente dirige...

Irmã Helena Moreira (HM) - O Colégio é uma Escola confessional, católica, pertencente à Província Portuguesa das Franciscanas Missionárias de Nossa Senhora. Está localizado na rua do Amial, freguesia de Paranhos, da cidade do Porto. Tem cerca de 1220 alunos distribuídos pelos diferentes níveis de ensino, desde o pré-primário ao secundário. Contamos com cerca de 85 docentes e 16 professores/monitores das activi- dades complementares e extra-curriculares....

Que são...

HM - Variadas: viola, judo, natação, ténis, ballet, entre outras. Contamos ainda com cerca de seis dezenas de funcionários que se distribuem pelas diversas áreas. Duas psicólogas e duas enfermeiras em serviço rotativo constituem o restante quadro de pessoal não docente.

As instalações são suficientes para dar resposta a esse número de alunos?
HM - Tanto não são que estamos em fase de ampliação e construção de novos espaços. No entanto, os três edifícios que constituem as actuais instalações do Colégio têm-nos permitido exercer o nosso trabalho. Temos, para além das salas de aula, laboratórios, salas de informática, salas de música, sala multimédia, cantina, bar, piscina, pavilhões gimno-desportivos, salas de atendimento, gabinetes, sala de convívio dos alunos, sala de professores, gabinete médico, auditório, gabinetes de psicologia, papelaria, reprografia, capela, campos de jogos, espaços interiores e exteriores

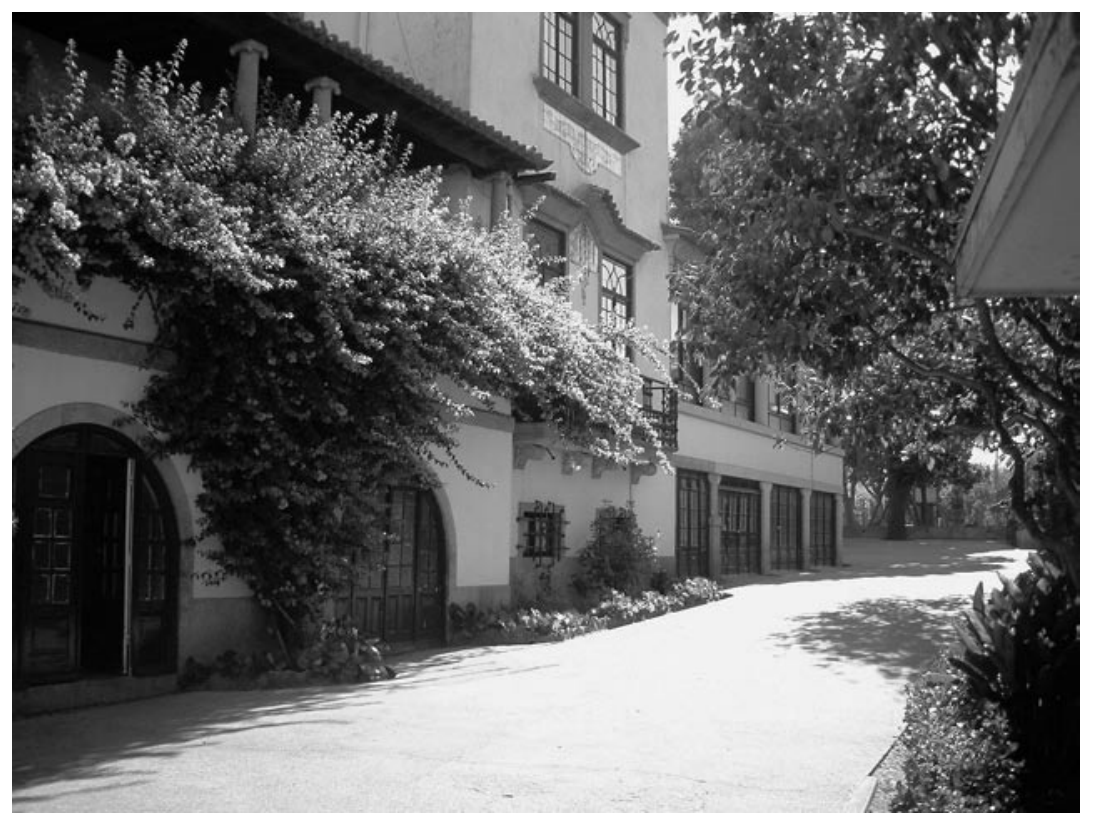

"Desde o átrio de entrada que se respira uma atmosfera de muita tranquilidade, calma e organização. Estamos no Colégio Luso-Francês, localizado na cidade Invicta". 


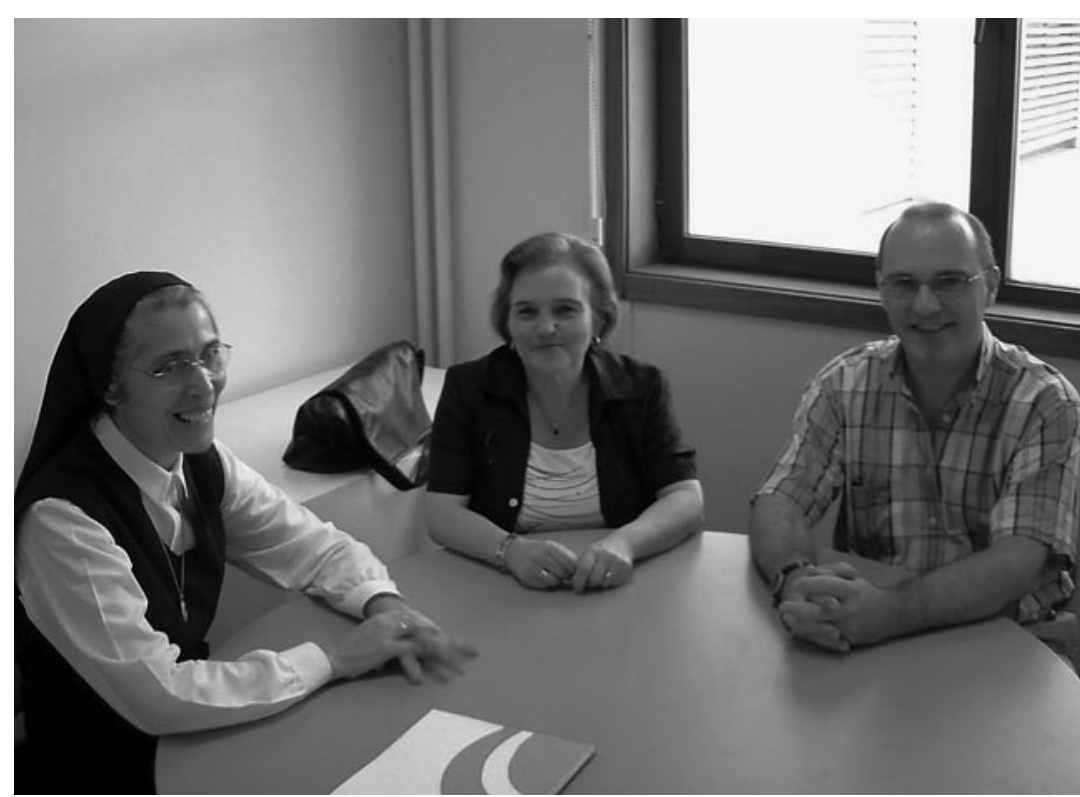

para recreio com parque infantil, sala de espectáculos e secretaria.

o que denota grandes investimentos para equipar todos esses espaços...

HM - Assim é. Todas as salas de aula estão devidamente equipadas com material adequado ao respectivo nível de escolaridade.

Quais são as grandes linhas do vosso projecto Educativo?

HM - A escola é, antes de tudo, um espaço privilegiado e vocacionado para o desenvolvimento e formação integral da pessoa humana. Quando se deixa a Escola, leva-se não só a aquisição de conhecimentos, mas também o ensaio que esta proporcionou para a inserção na sociedade nas suas diferentes dimensões. Nesta perspectiva o Colégio Luso-Francês, como escola católica, com ideário e características próprias, procura orientar o seu processo educativo para os seguintes objectivos gerais: educação para o crescimento espiritual e para os desenvolvimentos intelectual, afectivo, social e das expressões.

Das expressões? Qual o significado desse objectivo?

HM - A escola não só tem competência, como tem também obrigação de desenvolver todas as dimensões expressivas dos alunos, devendo fazê-lo de forma sistemática e coordenada tendo em consideração cada nível educativo.
Nesse sentido propomo-nos desenvolver as expressões artísticas: música, dança, teatro e a plástica; as expressões oral e escrita e o gosto pela leitura; a expressão motora e o gosto pelas actividades desportivas, as expressões tecnológica e audiovisual.

Li no átrio de entrada uma placa da APELF - Associação de Pais do Colégio - que dizia "Não basta ter começado, é preciso continuar". Gostaria que comentasse...

HM - Essa frase é da autoria de uma Superiora Geral logo, do início da Congregação. Entretanto, os pais entenderam que seria uma frase perfeitamente aplicável à situação, à realidade do Colégio. O Colégio apareceu em 1936, foi crescendo e, agora, realmente a frase surge como uma interpelação: não basta ter começado, é preciso continuar. Daí realmente o Colégio empenhar-se em cada ano em oferecer novas perspectivas e, como já afirmei, procurar fazer melhorias nas instalações, a níve de professores e alunos, motivar. Cumpre-nos dar continuidade a uma acção cada vez mais forte, mais vigorosa, que se imponha, não perante outros porque não temos esse objectivo, mas precisamente para formar jovens que se preparam para uma faculdade e para depois entrar no mundo, na sociedade, com fortes convicções, com saberes bem consolidados, virados para a investigação, para que possam dar um bom
A Madre Superiora e Directora Pedagógica, Irmã Helena Moreira, a Dr. ${ }^{a}$ Noémia Almeida professora do $12 .^{\circ}$ ano e o Dr. Carlos Azevedo, Coordenador do Departamento de Ciências Exactas, da Natureza e Tecnológicas (da esquerda para a direita). contributo para a construção de uma sociedade cada vez melhor.

Considera então muito feliz a iniciativa dos pais. Poderei daí inferir que considera a APELF de primordial importância neste Colégio? Cultiva-se a chamada dos pais à Escola e à participação neste projecto?

HM - Sem dúvida. A Associação está muito atenta, muito receptiva, muito colaborante às necessidades e às actividades do Colégio. É um parceiro nesta caminhada da Educação aqui no Colégio Luso-Francês a quem damos muita importância. Aliás, estamos neste momento com a revisão do Regulamento Interno e foram chamados a dar o seu parecer e a prestar a sua colaboração.

Carlos Azevedo (CA) - Aliás, se me é permitido, ainda este ano os pais proporcionaram uma actividade que considero extremamente interessante: disponibilizaram-se para que os nossos alunos pudessem ter contacto com o dia-a-dia das suas profissões, o que creio mesmo, levou alguns a decidirem por outras opções.

Como Directora Pedagógica, o que sentiu quando, de um momento para o outro, o seu Colégio passou a "andar na boca do Mundo" e a Irmã apareceu, se me permite, quase como "estrela" televisiva...

...risos generalizados... 
E por duas ordens de razão: por um lado, o 1. ${ }^{\circ}$ lugar obtido no ranking divulgado pelo Ministério e por outro pelas longas filas às portas do colégio na tentativa de se obter uma inscrição para frequentar o Luso-Francês.

HM - Bem...muito honestamente fujo bastante disso. Para além de sermos assediados pelos canais televisivos e pela imprensa escrita, concedemos espaço a alguns, a outros conseguimos...digamos...fugir. É que o nosso lema é trabalhar. Nunca estimulamos os alunos, nem falamos em termos de ranking. Apercebemo-nos que eles o vão assumindo, de tal modo que após o teste de matemática (1. a fase), uma aluna, que é uma daquelas alunas de "vintes", pensando que não iria ter o vinte e se ficaria pelo dezanove me disse: - "Oh Irmã, vai ser este ano que vamos deitar o Colégio abaixo"...

...gargalhada geral...

Portanto, eles têm isso em atenção mas nós não. Não gostamos nada do vedetismo, de chamar à atenção, nem de nos colocarmos à frente seja de que jeito ou razão for. O objectivo é mesmo trabalhar, é darmos o máximo em favor destes jovens...

\section{...os resultados vêm perfeitamente por acréscimo...}

HM - ...Sim, pelo trabalho que os professores realizam e também pela motivação deles...

No ano transacto o Colégio obteve óptimos resultados a Química. Há alguma receita especial?

Noémia Almeida (NA) - Não, não há nenhuma receita. Esses resultados devem- se à massa que encontramos; alunos com hábitos de trabalho e educação, o que é importante. Cumpridores. Tenho termo de comparação já que também lecciono no ensino oficial. As minhas aulas são exactamente as mesmas mas lá não tenho resultados tão bons.

\section{Mas isso normalmente está associado} a objectivos...

CA - Sim, os alunos aqui têm-nos bem definidos. Aqui traduz-se na entrada numa determinada Faculdade e lutam por isso. Enquanto nalgumas circunstâncias um 18 para alguns é motivo de alegria, aqui muitas vezes é de frustração.

\section{...ainda faltam dois...}

CA - Sim, mas para além disso querem compreender as coisas...

NA - ...cada um quer ser melhor...

CA - Têm gosto pelo que fazem, fazem exercícios até à exaustão, com gosto...

Essa vontade, o de fazer muito e bem, é-lhes incutida desde o $7 .^{\circ}$ ano...

NA - Muito mais cedo, desde os 3 anos de idade. Estava num festa de final de ano e tinha alunos que me diziam: "...Professora, eu não sei frequentar outra escola, estou cá desde os 3 anos... Como é que vai ser?..."

Mas a Físico-Química que se inicia no 7..$^{\circ}$ ano tem um trabalho coordenado que os motive para a Química e para que comecem logo com alicerces sólidos...

CA - Sim, pois aliados aos hábitos de trabalho que vão sendo desenvolvidos desde pequeninos, eles habituam-se a saber estudar, a ter o seu tempo, a organizar as actividades em função dos estudos. No caso da Físico-Química, especificamente, no $7 .^{\circ}$ ano apostamos muito, apesar da carga horária não facilitar a vidas aos professores, na experimentação. Para eles a Química é uma festa de cores, de cheiros, de fumos....atrai-os imediatamente. Eles ficam rendidos...

\section{...É mágica...}

NA - Aqui tenho de fazer a crítica ao fim das técnicas laboratoriais...

CA - Sim, embora depois a parte teórica não os entusiasme tanto. Mas se começarmos aqui a levar as coisas a bom porto, eles no secundário já encaram a Química com gosto. Procuramos levar a ciência aos mais novos.

O 2. Iugar nacional nos resultados de Química teve, com certeza, reflexos positivos...

CA - Claro, deixaram-nos a todos satisfeitos. Além de que, para surpresa nossa, a Hovione, empresa da indústria química ligada à indústria farmacêutica, sediada em Loures, reconhecida pela FDA e com fábricas e sucursais em vários países, premiou-nos com uma visita às suas instalações e com material de laboratório.

\section{...interessante essa atitude...}

CA - Sim, de facto ao premiar as 5 escolas com os melhores resultados nacionais e apoiar da mesma forma as escolas do concelho de Loures é um serviço à comunidade que me parece interessante e estimulante.

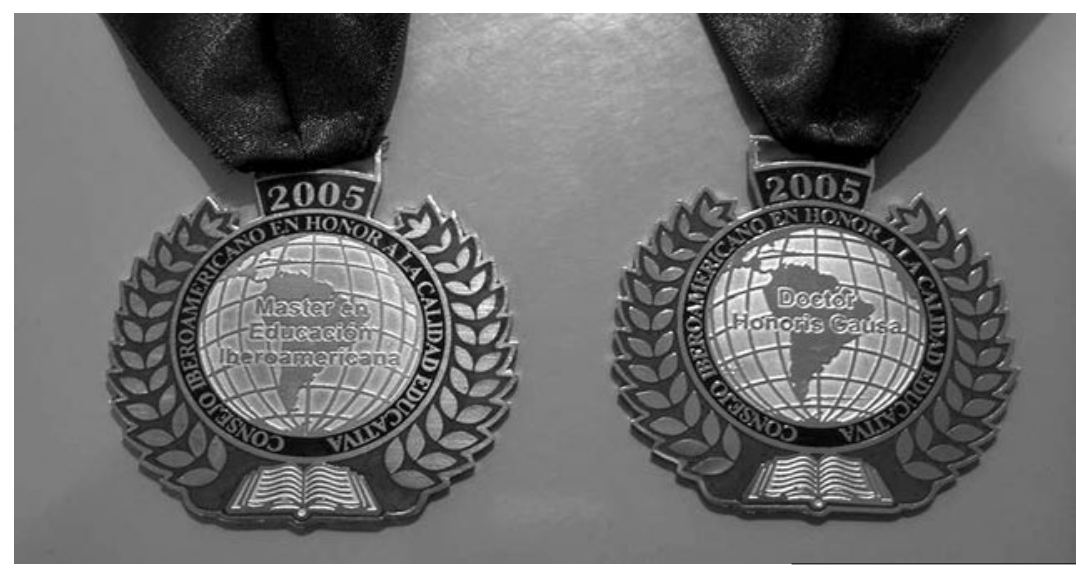




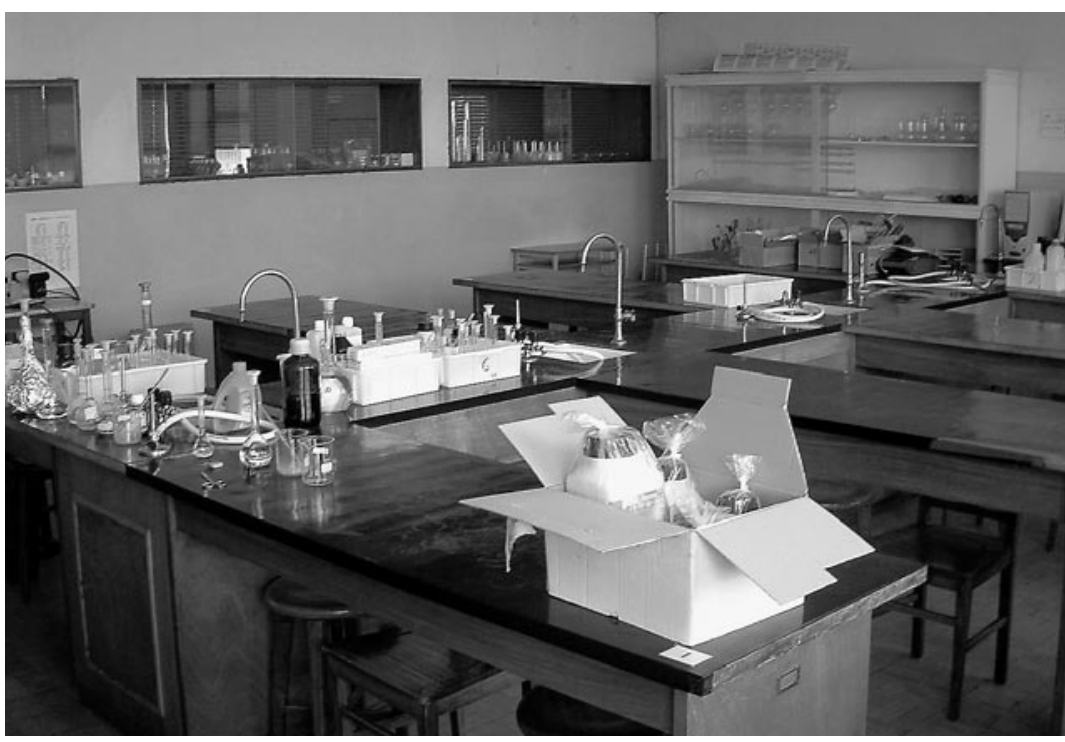

Que opiniões têm sobre a forma como está organizada curricularmente a Físico-Química no ensino básico?

CA - É evidente que o tempo é escasso. Aqui não desdobramos as turmas pelo que temos de ser criativos e imaginativos para podermos executar trabalhos práticos. A dificuldade de espaço físico, aliado ao tempo lectivo disponível, torna a situação complicada. Mas gostamos de pôr os miúdos a mexer nos tubos de ensaio, nos gobelés embora seja, como referi, difícil. Esperamos por novas instalações.

A Dr. ${ }^{a}$ Noémia referia-se há pouco ao fim das técnicas...

CA - Este ano leccionei o $10 .^{\circ}$ ano pela segunda vez, com o novo programa, agora já com a estrutura curricular adequada, com um bloco desdobrado para actividades laboratoriais. Acho que foi um bom complemento. Vamos ver como corre o próximo $11 .{ }^{\circ}$.

Mas os alunos que não vão ao laboratório no básico...

CA - Aí sim, poderemos ter sérias dificuldades para cumprir o que está no programa. O tempo para ensinar pela primeira vez a fazer relatórios, trabalhar dados, fazer gráficos... tornará tudo mais difícil. Seguramente o tempo não chegará.

\section{Têm participado em projectos?}

CA - Participamos no Nónio.
E no Ciência Viva? Consideram que devia regressar?

NA - Creio que sim. Foi uma experiência interessante e faz falta às escolas.

\section{E nas Olimpíadas de Química?}

CA - Aí sim. Participamos nas dos mais velhos e nas Olimpíadas Júnior. Não era costume mas temos aumentado a participação. Nas de Física é que temos um aluno seleccionado para nos representar no estrangeiro.

CA - Gostava de deixar um alerta para o que se possa vir a passar no próximo 11. ${ }^{\circ}$ ano. Nas hipotéticas questões de exame já divulgadas, levantam-se algumas questões que talvez não tenham sido, por muitos, abordadas da melhor forma. Aqui vamos fazer esse reajustamento.

NA - Pelo que vi há perguntas que não avaliam conhecimentos.

E sobre o $12 .^{\circ}$ ano, algum comentário?

NA - Tenho grande receio do que pode vir a acontecer à Química. Prevejo que quer a Química quer a Física fiquem muito reduzidas. Por facilitismo, os alunos não optarão por uma disciplina que Ihes dá trabalho e sobre a qual não terão que prestar provas. Vão ser disciplinas a evitar. Optarão por disciplinas mais fáceis que possam dar menos trabalho.

Isso, reflectir-se-á , a jusante, nas Faculdades...
Que perspectivas para o próximo ano? "...criar novas instalações para oferecer espaços mais actualizados, como sejam os laboratórios".
NA - Sim. Se já agora os professores se queixam, imagine no momento em que os alunos ingressarem com menos horas de Química. Vão ter mais razões de queixa.

Estes programas são menos exigentes?

NA - Claro, como o programa é em mero contexto não é preciso aprofundar muito. É tudo pela rama. Isto terá consequências...Não estou muito de acordo com esta orientação. Nem dos programas nem da própria reforma que está a entrar no ensino secundário.

Os exames de $12 .^{\circ}$ ano merecem-lhe algum comentário?

NA - Permita que conteste algumas questões da maneira como foram colocadas mas essencialmente os critérios de correcção: facilitam erros e penalizam em 100\% pormenores mínimos...e erros científicos graves não são penalizados porque o objectivo da questão não era saber isso. O Dr. Carlos Corrêa também já fez alguns comentários interessantes...

Mas voltando um pouco atrás, será esta dinâmica um dos factores que terá motivado aquelas filas à porta do Colégio...

HM -...sinceramente, aquilo incomodou-nos imenso. Achamos que foi um certo exagero. No entanto, poderá mostrar quais são os objectivos que presidem à escolha de um estabelecimento de ensino por parte dos Encarregados 
de Educação. Vão atrás de miragens... Foi muito bem classificado, então vamos para ali. Imaginemos que este ano não ficamos numa posição tão cimeira. Isso vai traduzir que descemos em qualidade? Estou segura que não. Tudo isso depende dos objectivos dos alunos. No ano anterior tínhamos um grande grupo que queria medicina. Este ano, o grupo para as engenharias é maior. Não precisam de médias tão altas. Os alunos ainda são novos e não percebem que a nota, para além de traduzir uma possibilidade de entrar na Faculdade desejada, pode e deve também ser espelho de saberes bem consolidados que thes poderá conferir uma maior segurança no seu percurso universitário. A escoIha do estabelecimento deveria ser feita em função do projecto, do ideário, da qualidade.

Para evitar essas fileiras, na revisão do Regulamento Interno do Colégio, estamos a redefinir os critérios de admissão e as modalidades de fazer a pré-inscrição.

Mas é difícil vir estudar para o Colégio Luso-Francês?

HM - Só pelo facto de não existirem vagas. É evidente que os rankings vieram acentuar aquele mito que o Colégio Luso-Francês...

Tem acesso directo à Faculdade...

...risos....

Como Directora Pedagógica considera que existem diferenças acentuadas na forma de trabalhar no ensino privado e no público?

HM - Sim. Tenho consciência que no ensino público também há muitos bons professores e escolas que se procuram organizar e que funcionam razoavelmente. Nós talvez tenhamos vantagem pela estabilidade do corpo docente. Há um maior acompanhamento dos alunos ao longo dos ciclos. Isso pode criar uma relação afectiva, um estímulo e uma motivação superiores. Depois, o próprio professor conhece o aluno em termos de capacidades. Assim sendo, há aquela exigência: " Tu és capaz de dar mais!", aumenta a motivação. No ensino público poderá faltar esse acompanhamento. Temos também na maioria dos casos alunos motivados, com objectivos bem definidos. Isso faz com que tenham motivação para o trabalho, adiram a propostas e se empenhem...

NA - ...Mas isso é o Colégio que faz. A maior parte deles estão aqui desde os três anos de idade e o Colégio motiva-OS...

...todas as multi-actividades proporcionadas desde a pré-primária contribuem para essa forma de estar quando mais velhos...?

NA - Claramente. Trabalho também no ensino público e a massa que encontro em ambos os lados não tem nada a ver. Vêm motivados, bem formados, com hábitos de trabalho e de estudo que os outros não trazem $E$ isso é o próprio Colégio que faz.

HM - Há um acompanhamento e uma exigência desde a base. Temos ainda uma grande ajuda do gabinete de psicologia. As duas psicólogas ajudam mesmo na ligação com as próprias famílias, na detecção de dificuldades na aprendizagem... são um apoio fundamental. As conversas que mantêm com os Professores também são importantes: dificuldades em família...

NA - ...Dificuldades pessoais...

HM - ...Tudo isso faz com que os alivie de uma carga emocional, afectiva que muitas vezes trazem. Essas cargas afectam-nos numa disponibilidade interior para concentração e atenção.

As medidas anunciadas pelo Ministério sobre a presença dos professores na escola seriam desnecessárias no Luso-Francês?

HM - Certo...tenho consciência que os professores não medem o tempo que dão à Escola. Naturalmente, têm a sua vida profissional que se pode estender para além do Colégio, têm os seus compromissos familiares, mas na realidade sinto que, se eles pressentem que a Escola deles necessita, os professores não medem o tempo que cá passam. Temos óptimos colaboradores.

Mas a Irmã tem consciência que isto está tudo muito bem organizado. No átrio respira-se tranquilidade e verifi- ca-se a existência de muita informação disponível e organizada...

HM - ...procuramos... procuramos...

Poder-se-ia dizer que aqui se trabalha para a excelência para se fazer sempre mais e melhor...

HM - Certo. Realmente trabalhamos nesse sentido sem pensar no reconhecimento exterior mas ficamos satisfeitas quando é reconhecido. Há quinze dias regressei do Uruguai com um professor do Colégio pois fomos premiados pelo Conselho Ibero-Americano da Excelência Educativa. Foi algo com que nunca contamos. Foi a primeira vez que Portugal foi distinguido e para além de nós esteve o Colégio dos Carvalhos, a Universidade Fernando Pessoa, a Universidade do Vale do Sousa e um Instituto Profissional de Lisboa. Fomos os cinco distinguidos.

\section{Estão em processo de certificação?}

HM - Estamos a trabalhar para isso. A empresa que trabalha connosco não tem sido tão diligente quanto desejaríamos. Mas pessoalmente não vejo grandes vantagens nisso. Continua no entanto de pé a intenção.

Não tem sido algo que nos preocupe em demasia.

Três objectivos para o futuro...

HM - Continuar a dar o melhor ao nível dos nosso jovens, adolescentes e crianças. Trabalhar com esta equipa de professores que é jovem, dedicada e efectiva. São membros do Colégio, são companheiros de viagem; criar novas instalações para oferecer espaços mais actualizados, como sejam os laboratórios; criar mais intercâmbio com o estrangeiro para Ihes oferecer o contacto e experiências com um mundo, que julgo, mais aberto do que o nosso.

Três palavras para definir o Colégio...

HM - Labor, Caritas, Fides. Trabalho apaixonado, o amor que sempre presidiu à causa e a fé que poderemos ligar a Jesus Cristo, mas também uma fé na vida, uma esperança de que estamos a construir jovens para trabalharem e construírem uma sociedade melhor. 